\title{
Digital adaptation of the Russian payment services market to pandemic shocks
}

\author{
Olga Korobeynikova ${ }^{1, *}$, Dmitry Korobeynikov ${ }^{2}$, Tatiana $_{\text {Dugina }}{ }^{2}$, Zinaida Kozenko $^{2}$, and \\ Svetlana Shaldokhina ${ }^{2}$ \\ ${ }^{1}$ Volgograd State Technical University, 400005, Lenina Avenue, 28, Volgograd, Russia \\ ${ }^{2}$ Volgograd State Agrarian University, 400002, University Avenue, 26, Volgograd, Russia
}

\begin{abstract}
The purpose of the article is to identify and substantiate the features of adaptation of the Russian payment services market to pandemic shocks, taking into account digitalization trends. The following regularities were revealed: increasing rates of digitalization; structural transformations of the market; blurring the lines between banking products and fintech services amid heightened competition; the emergence of payment services for retailers; growing demand for e-commerce, online transactions and contactless payment for services; increasing financial inclusion of traditional and innovative retail financial services; formation of an ecosystem approach, etc. It is concluded that the ongoing changes have a positive impact on the transformation of the market supply of payment services. In the context of the COVID-19 pandemic, payment intermediaries are using tactics of digital settlement services and reducing dependence on loan products; promoting an initial positive customer experience in remote channels, mobile applications; focusing on sustainable development of the client base.
\end{abstract}

\section{Introduction}

The modern payment services market is subject to rapid changes that are transformational. The changes are associated with the emergence of digital innovations that are being applied in the payments field faster than in other areas. Also, transformations occur due to epidemic, technological, sociocultural and other factors. These factors have made notable changes not only in the ecosystem landscape, the structure of the financial services market, product offerings, but also accelerated the ongoing transformations.

Digitalization was a major driver of changes in the payments market before the pandemic. The COVID-19 pandemic has caused previously unknown shocks and has become a major factor now affecting the payments market and its participants. During the pandemic in Russia and the economic shocks they provoked, there was an explosive growth in the number and volume of remote payment transactions. We can say that one of the main trends in the payment market in 2020 was the growing pace of digitalization. Digitalization manifests itself at all levels - at the level of business organization of payment systems,

* Corresponding author: korobeinikov77@yandex.ru 
payment providers, payment services, at the level of developing new digital products that would meet the changing needs of consumers.

A feature of the payment market is the ability to intensively diffuse innovations into the internal environment, which causes transformations in other related areas. As a result, marketing approaches and marketing proposals, external communication technologies, methods and techniques of internal generalization, processing, transfer and storage of data, organizational structure, etc. are changing. As a result, financial institutions become capable of transferring and accelerating digital innovation to the external environment - to retail consumers of payment services. Consumers are developing a distinct digital consumer culture.

The preconditions for the digital economy were formed even before the pandemic. These prerequisites include: a high level of availability of payment infrastructure and payment services [1], an increase in financial literacy among the population, the creation of digital ecosystems by leading banks, the emergence of digital practices among entrepreneurs [2], the transfer of most public services to digital format [3], a system of quick payments of the Bank of Russia and others has been created. Traditionally, universal commercial banks are a monopolist in the payment market of Russia. In recent years, they have faced strong competitive pressure from FinTech companies and BigTech companies. The payment market is undergoing a structural transformation of the supply of payment services: new niches with new (neo) participants appear, traditional financial niches are expanding and merging with non-financial ones. Under the influence of the pandemic, transformations are becoming even more visible. External unpredictable shocks change the market landscape and break the usual stereotypes in the nature of consumer behavior, consumer preferences, in the labor market, etc. [4], [5]. As a result, a situation has actually developed in which the theory of payment relations and the payment market lags behind the practice of organizing payment communications, creating and promoting financial services, developing forms and methods of symbiosis of financial, commercial and industrial capital, methods of self-organization and self-regulation, etc.

According to the Bank of Russia, $81.7 \%$ of adult Russians have bank cards; over the past five years, the share of non-cash payments in retail payment turnover has increased more than 2.5 times, the share of non-cash payments amounted to $69 \%$ in the first half of 2020. In the pre-pandemic period, many retail consumers ("underbanked") did not use the available digital services (for example, they received a salary on the card, but withdrew all the money to pay in cash, or opened a deposit in the bank in person, although they could do it in the application, etc.). With limited physical accessibility and movement during the pandemic, the proportion of users of online services increased significantly (especially those users who first started using digital services). According to a study conducted by the MasterCard payment system, $97 \%$ of users of payment services in Russia use banking applications: $77 \%$ - mobile applications of traditional banks, 33\% - applications that track funds in different accounts, and applications of digital banks. The Russian financial company QIWI conducted a study of the Russian non-cash payments market in the second quarter of 2020. According to the research, the payment turnover on virtual cards in the Russian market grew by $44 \%$ compared to the first quarter of 2020 . The average transaction amount for virtual cards increased by $12 \%$ (to $\$ 140$ ). If in the second quarter of 2019 , users made 11 transactions on average using a digital card, then in 2020 for the same period already 19 transactions. These data indicate that the payments sector has been less affected by the COVID-19 pandemic than other areas. The payments sector has a chance to realize growth opportunities thanks to its ability to quickly adapt to the external environment.

The aim of the study is to identify and substantiate the features of adaptation of the Russian payment services market to pandemic shocks, taking into account digitalization trends. 
Research objectives: 1) to identify the features and assess the dynamics of changes occurring in the Russian payment market under the influence of the pandemic, the reaction of banks to new shocks; 2) highlight the main trends in the transformation of payment services in the Russian market in the context of pandemic shocks.

\section{Materials and Methods}

The study uses a systematic approach and theoretical methods for generalizing and comparing data, a structured description of the characteristics of the Russian payment services market. The study of the peculiarities of adaptation of the Russian market of payment services to pandemic shocks is based on general methodological scientific principles: the unity of theory and practice; historical approach; objectivity; complexity; consistency.

An analysis of the study of the problems outlined in the article showed that the theory and methodology of national and global payment markets, payment services were considered in the works: Averchenko OD [6], Bech ML, Hobijn B [7], Elmquist M, Gawer A, Le Masson P [8], Ercevik K, Jackson J [9], Leinonen H, Soramaki K [10], JE Stiglitz [11] and others. Market risks and methods of their minimization were studied by A.V. Babkin, D.D. Burkaltseva, V.V. Pshenichnicov, A.C. Tyulin [12], Ivanov PI, Burkaltseva DD, Arzumanov RM, Grischenko LL, Zhirnov YuN, Pestov NN, Oleynik AS, Uryadov YuYu [13], Skokov RYu [14] and others. The digital economy and problems of digital transformation of the financial sector are devoted Akimova OE, Volkov SK, Kabanov VA, Ketko NV, Kuzlaeva I. [15], Gawer A, Cusumano M [16], Masiukiewicz Piotr, Dec Paweł [17], Muegge S. [18], Volkov SK, Gushchina EG, Vitaleva EM [19] and others. However, with the emergence of new risks and pandemic shocks caused by these risks, new questions arose that require additional research - adaptation of the payment services market to pandemic shocks in the context of the development of the digital economy.

\section{Results}

Modern participants in the payment market both in Russia and in developed countries are characterized by an active transformation of business processes, the development of omnichannel and mobile financial applications integrated into segments of non-financial services (for example, retail) based on open banking (API), the creation and launch of technologies blockchain [20], artificial intelligence, robotization, biometric identification, machine learning. To this end, Russian banks use seamless technologies for attracting and servicing customers, cooperation with fintech companies, and intersegment integration [21]. The crisis provoked by pandemic shocks, as well as the decline in business activity in the Russian economy in the second, third and fourth quarters of 2020, has significantly accelerated this process.

It was found that in the face of falling profitability of traditional business due to the pandemic, Russian banks develop in two ways. The first is further digitalization of business processes to reduce operating costs and digitalization of all traditional services, and the second is the creation of digital ecosystems to attract an additional customer base by joining partner digital services via API.

Bank customers can receive most of the services and banking products without visiting branches, but using marketplaces and remote identification. Russia is actively developing the Unified Biometric System and remote video identification as part of the state project the Unified System of Identification and Authentication. Even small and medium-sized 
Russian banks can provide their clients with full-fledged remote service using outsourcing of third-party certified companies.

The physical presence of traditional payment intermediaries in the regions of Russia is decreasing. Instead, omnichannel service is expanding through online service. We see successful examples of the transformation of offline services into online services in the largest state-owned banks (Sberbank, VTB, etc.), which create their own digital ecosystems and open platforms. Neobanks (digital banks) are focused on online service - Tinkoff, Tochka Bank, MTS Bank, etc., which initially did not open territorial offices and worked exclusively online. For example, during the period of pandemic restrictions in the 2nd quarter of 2020, the share of remote settlement operations of retail clients in the VTBOnline application approached $100 \%$. More than $99 \%$ of operations in the brokerage business are also carried out by VTB Bank online. VTB Bank sets a strategic goal - in 2022 , transfer of $100 \%$ of products for individuals to online channels.

The Bank of Russia, while reforming the market, monitors the maintenance of a competitive environment. The Russian banking system is actively pursuing an open banking policy. The Second European Directive PSD2 was adopted as a guideline. For traditional offline banks, open banking has created risks of customer abandonment through the expansion of consumer ecosystems. Among the new players are large retail companies that are building large-scale ecosystems of consumption (for example, in the sales and lending of household appliances, electronics, etc.). In this situation, traditional banks were ousted from the new market, leaving behind only a niche of credit products.

The most obvious increase in payment transactions in the retail segment occurs in the fast payment system of the Bank of Russia (SBP). The system was created in early 2019 based on the international standard for the exchange of electronic messages between financial institutions (ISO 20022). It provides instant transfers of funds to the accounts of retail customers of different banks using a simplified identifier (phone number), as well as access to the virtual space in online and offline modes. The fast payment system is innovative, it uses universal instruments and accounts to conduct transactions regardless of the type of payment system. The fast payment system is a universal platform infrastructure solution. It can be called a driver of the payment market, which is confirmed by quantitative indicators (Table 1).

Table 1. Indicators of money transfers through the fast payment system (SBP) service

\begin{tabular}{|l|c|c|c|c|c|c|}
\hline \multirow{2}{*}{ Indicators } & \multicolumn{4}{|c|}{2019} & \multicolumn{2}{c|}{2020} \\
\cline { 2 - 7 } & Q I & Q II & Q III & Q IV & Q I & Q II \\
\hline Quantity, million units & 0.1 & 0.9 & 1.9 & 3.8 & 5.1 & 8.3 \\
\hline Volume, bln RUB & 0.4 & 8.3 & 17.2 & 33.6 & 39.8 & 71.5 \\
\hline
\end{tabular}

During the period of its operation, the system of quick payments showed high growth rates of operations. The number of payments in the second quarter of 2020 reached 8.3 million units. and 71.5 billion rubles. In the crisis second quarter, chain growth rates increased to $62.75 \%$ in terms of the number of transactions and $79.65 \%$ in terms of transactions. For comparison: in the first quarter of 2020 compared to the fourth quarter of 2019 , the growth rates were $34.21 \%$ and $18.45 \%$. The achieved dynamics is due, among other things, to the influence of external pandemic shocks.

Fast payment technology is used by global payment systems (such as Mastercard), large and medium-sized Russian banks. As of the beginning of the third quarter of 2020, 183 banks, about 9 million private users, about 41 thousand trade and service enterprises and individual entrepreneurs were included in the fast payment system. In the future, on its basis, it is planned to create a decentralized payment system covering the entire financial market. 
We also associate the adaptation of the payment services market to pandemic risks with the functioning of the marketplace platform for remotely receiving financial services and comparing their costs. The platform was developed by the Bank of Russia. The Marketplace will allow payment market participants to expand the circle of new customers and increase competition in the financial market. For consumers of services, the marketplace makes it possible to arrange financial products online through the aggregator showcases of existing portals (for example, Banki.ru, Compare.ru, etc. are popular). For Russia, this project is very important, since the country has not yet overcome the territorial inequality in the availability of financial services. Financial inequality can be eliminated through the marketplace. Interaction between the client and the seller of financial services is provided by special platforms: Moscow Exchange and VTB Registrar, which offer deposits and bonds; the Infinitum depositary sells shares of investment funds, etc.

There are a number of patterns on the Russian market, the influence of which has increased under the influence of pandemic risks. These patterns take on the character of trends:

1. Digitalization and the growth of its pace. Digitalization manifests itself at all levels of the payment market - from business organization to the development of innovative products that meet the complex needs of payment service consumers. The transformation of the offer of payment services can be represented as: physical branches $\rightarrow$ contact centers $\rightarrow$ mobile applications $\rightarrow$ internet banks $\rightarrow$ voice assistants $\rightarrow \ldots$.

2. Constant structural transformations of the payment market. Transformations are manifested in the emergence of new participants - fintech companies, which not only enter the market, but also strengthen their competitive positions. Fintech companies can easily adapt to new conditions, because they operate on a digital-first model and do not have the legacy that traditional banking intermediaries have accumulated. But banks and large payment platforms have another advantage - diversification. They offer a wide range of comprehensive services. Smaller traditional banks that offer niche services are less balanced and more vulnerable.

3. Blurring the lines between banking products and fintech services amid intense competition. Banks are transforming into IT companies and creating their own technology platforms. Neobanks turned into full-fledged market players who were perceived as real competitive participants.

4. The emergence of internal payment services of the largest retailers (BigTech companies) based on local platforms of specific retail structures.

5. Growing demand for e-commerce, online transactions and contactless payment services. The growth is taking place against the backdrop of a decline in offline transactions among retail users. In the context of the pandemic and isolation, most retail consumers of services for the first time began to make purchases on the Internet, pay for services online and receive services from banks remotely.

6. Increased financial inclusion of traditional retail financial services and new services and services in the retail segment. The growth was catalyzed by pandemic shocks and isolation of service consumers. Retail consumers have a high level of financial literacy. This is a prerequisite for abandoning cash and using digital services (mobile banking, fast payment systems, online services, and others).

7. The growing popularity of online payments is naturally causing the growth of related financial services. Banks and fintech companies began to focus on the development of products in the areas of compliance, digital identity, information security, antifraud and risk management. KYC systems have become very popular, especially products for remote verification of counterparties.

8. Growth in the spread of payment innovations in the consumer segment: fast payments, QR technologies, Open banking, API, etc. 
9. Building financial ecosystems based on digital innovation and traditional banking business models. In Russia, there are two features of the maturation of ecosystems. First, the largest state banks are the creators of ecosystems. Secondly, banks that create ecosystems monopolize the market and do not want to open interfaces for the use of ecosystems by other market participants. That is, closed ecosystems are created, the participants of which are entities affiliated with each other.

10. Seamless payment processes for consumers and retailers, hyper-localization and hyper-customization of payments. Processes are tailored to the requirements of the country or regional market and local audience.

11. Decrease in commission income of banks from payment transactions as a result of a decrease in payment activity due to the pandemic. In the Russian payment market, there is a clearly epidemic situation that improved in the summer of 20 , there is a correlation of systems since 20 and again became in the fall of 2020. The second wave of the pandemic has reduced the resources of small retailers who are forced to liquidate. As a result, the flow of payments for goods and services has decreased.

To overcome negative trends and use new opportunities that the COVID-19 pandemic has provided, Russian banks and other payment intermediaries use the following tactics:

- form a marketing product strategy focused on digital settlement services and reducing dependence on credit products;

- actively contribute to the initial positive customer experience in remote channels, mobile applications;

- focus on sustainable development of clients: their financial consulting, involvement in the bank's ecosystem, joint risk management of clients.

\section{Conclusions}

The transformation of the Russian payment market is taking place dynamically against the rapidly changing and poorly predictable backdrop of the COVID-19 pandemic. The pandemic has significantly accelerated digital transformation, changes in the ecosystem, market structure, and product offerings. Payment market participants are characterized by the transformation of business processes, the development of omnichannel and mobile financial applications integrated into the segments of non-financial services based on open interfaces, the creation and launch of new effective blockchain technologies, artificial intelligence, biometric identification, and machine learning to the market. The revealed patterns form stable long-term trends, which enhances the viability of payment market entities using digital technologies.

\section{References}

1. O. M. Korobeynikova, D. A. Korobeynikov, L. V. Popova, O. V. Savina, R. S. Kamilova, Espacios (2017)

2. J. E. Stiglitz, https://www.project-syndicate.org (2020)

3. V. S. Kokhanova, K. S. Bohon, Scientific Bulletin of the Southern Institute of Management, 84 (2019)

4. R. Levine, N. Loayza, T. Beck, Journal of Monetary Economics, 31 (2000)

5. R. Nelson, E. Phelps, American Economic Review, 69 (1996)

6. O. D. Averchenko, Economics. Business. Banks, 87 (2018)

7. M.L. Bech, B. Hobijn, International Journal of Central Banking, 147 (2007)

8. M. Elmquist, A. Gawer, P. Le Masson, European management review, 417 (2019) 
9. K. Ercevik, J. Jackson, The Quarterly Review of Economics and Finance, 1 (2009)

10. H. Leinonen, K. Soramaki, Bank of Finland Discussion Papers, 1 (1999)

11. J. E. Stiglitz, Finance: Theory and Practice, 6 (2020)

12. A. V. Babkin, D. D. Burkaltseva, V. V. Pshenichnicov, A. C. Tyulin, Journal of Economics, 9 (2017)

13. P. I. Ivanov, D. D. Burkaltseva, R. M. Arzumanov, L. L. Grischenko, Yu. N. Zhirnov, N. N. Pestov, A. S. Oleynik, Yu. Yu. Uryadov, International Journal of Innovative Technology and Exploring Engineering, 4266 (2019)

14. R. Yu. Skokov, The European Proceedings of Social \& Behavioural Sciences EpSBS, 1106 (2018)

15. O. E. Akimova, S. K. Volkov, V. A. Kabanov, N. V. Ketko, I. M. Kuzlaeva, WSEAS Transactions on Environment and Development, 397 (2020)

16. A. Gawer, M. Cusumano, J. Prod. Innov. Management, 417 (2014)

17. Piotr Masiukiewicz, Paweł Dec, Economics. Law. State, 18 (2019)

18. S. Muegge, Technology Innovation Management Review, 5 (2013)

19. S. K. Volkov, E. G. Gushchina, E. M. Vitaleva, Regional and Sectoral Economic Studies, 45 (2019)

20. D. Burkaltseva, O. Sivash, O. Boychenko, L. Savchenko, T. Bugaeva, S. Zotova, European Research Studies Journal, 366 (2017)

21. L. Popova, D. Korobeynikov, O. Korobeynikova, A. Panov, Journal of Applied Economic Sciences, 1034 (2016) 